\title{
Concentrações e cargas de nitrato e fosfato na Bacia do Ribeirão Concórdia, Lontras, SC
}

\author{
Adilson Pinheiro', Vander Kaufmann', Danieli Schneiders', \\ Daniela A. de Oliveira' ${ }^{1}$ \& Renata M. R. Albano ${ }^{1}$
}

\begin{abstract}
RESUMO
Neste trabalho foram determinadas as concentrações e as cargas de nitrato e de fosfato inorgânico total, na água de escoamento superficial, de drenagem e subterrânea, na bacia do Ribeirão Concórdia, Lontras, SC. Foram coletadas 102 amostras durante 109 dias, em três seções fluviométricas, três lisímetros e três poços piezométricos, distribuídos no interior da bacia. As concentrações foram comparadas com os padrões estabelecidos nas Resoluções CONAMA n ${ }^{\circ}$. 357/2005 e nº. 420/2009. As concentrações de nitrato e de fosfato no escoamento e drenagem dos lisímetros foram maiores que aquelas das seções fluviométricas e dos poços piezométricas. Nas seções fluviométricas e no escoamento superficial do lisímetro com pastagem as concentrações de nitrato foram inferiores aos padrões estabelecidos para essas águas. As concentrações de fosfato nas seções fluviométricas e nos lisímetros tanto do escoamento superficial quanto da drenagem e nos piezômetros, superaram os padrões das Resoluções CONAMA nº. 357/2005 e nº. 420/2009. As águas de drenagem nos lisímetros transportaram cargas de nitrato e de fosfato superiores àquelas do escoamento superficial; estas, por sua vez, transportaram cargas similares às dos rios.
\end{abstract}

Palavras-chave: qualidade da água, monitoramento ambiental, fluxo de nutrientes, bacia agrícola

\section{Concentrations and loads of nitrate and phosphate in the Ribeirão Concórdia river basin, Lontras, SC}

\begin{abstract}
This study presents concentrations and loads of nitrate and total inorganic phosphate in surface runoff infiltrating water and subsurface flow in the basin of Ribeirao Concordia, Lontras, SC - Brazil . Over a 109-day period, 102 samples were collected from three river sections, three lysimeters and three piezometric wells in the interior of the basin. Concentrations were compared with the standards given in the CONAMA Resolutions 357/2005 and $420 / 2009$. Concentrations of nitrate and phosphate in lysimeter drainage water and flows were greater than those in river sections and piezometric wells. In the river sections and in surface flow from the lysimeter under pasture, nitrate concentrations were lower than the benchmarks set for such waters. Phosphate concentrations in the river sections and in both lysimeter surface runoff and in drainage water, and in the piezometers, all exceeded the standards defined in CONAMA Resolutions 357/2005 and 420/2009. Drainage waters in the lysimeters transported nitrate and phosphate loads greater than those in surface runoff, which in turn transported loads of the same order of magnitude as in river flow.
\end{abstract}

Key words: water quality, environmental monitoring, nutrient flux, agricultural basin 


\section{INTRODUÇÃO}

Lagos, represas e rios, são as fontes mais valiosas de água potável (Souza et al., 2007). Sabe-se, que a diminuição da qualidade dessas águas, é decorrente da poluição causada por diferentes fontes, tais como efluentes domésticos e industriais e escoamento superficial urbano e agrícola. Além disto, em áreas agrícolas, os poluentes transportados pelo escoamento superficial são constituídos de sedimentos, pesticidas e nutrientes. Os nutrientes potencializam o desenvolvimento do processo de eutroficação, dos mananciais de águas superficiais, que são altamente impactantes, sendo que, para as condições brasileiras, poucos trabalhos mensuraram o quanto os poluentes de origem agrícola contribuem para a degradação dos recursos hídricos (Merten \& Minella, 2002). Já nos Estados Unidos da América e segundo levantamento da United States Environmental Protection Agency (USEPA) estima-se que 50 e $60 \%$ da carga poluente que degrada lagos e rios, respectivamente, são provenientes da agricultura (Gburek \& Sharpley, 1998).

A qualidade da água depende do uso para ao qual ela se destina. Ela pode ser afetada pelas alterações que ocorrem na bacia, sejam de origens antrópica ou natural (Toledo \& Nicolella, 2002). Entre os parâmetros usados para a classificação da qualidade de águas superficiais e/ou subterrâneas ressalta-se a concentração de diferentes espécies químicas que atuam como nutrientes no crescimento vegetal. As Resoluções $n^{\circ} .357$ e n ${ }^{\circ}$. 420 do Conselho Nacional do Meio Ambiente (CONAMA, 2005 ; 2009) estabelecem padrões para a classificação das águas superficiais e subterrâneas, respectivamente, em função das concentrações das espécies químicas presentes na massa líquida, dentre quais se situam o nitrato e o fósforo total, cujos limites de nitrato se encontram em ambas as resoluções na concentração de $10 \mathrm{mg} \mathrm{L}^{-1}$. Para o fósforo total somente a Resolução $\mathrm{n}^{\circ}$. 357/2005 estabelece limites de concentração variando entre 0,02 e $0,15 \mathrm{mg} \mathrm{L}^{-1}$, dependendo do ambiente e da classe do corpo de água.

Desta forma, estudos buscando a avaliação da concentração de constituintes da água são requeridos no processo de gestão ambiental e de recursos hídricos (Pinheiro \& Deschamps, 2008), como, para alertar a sociedade e fornecer subsídios para o melhor planejamento das atividades agrícolas.

Neste processo, as alterações ocorridas em uma bacia hidrográfica podem ser avaliadas por meio de suas características físicas (Teodoro et al., 2007; Pinto et al., 2005) e do monitoramento de parâmetros de qualidade de águas superficiais (Monteiro \& Pinheiro, 2004; Souza et al., 2000). Além disto, pode-se avaliar a distribuição espacial de fontes de poluição difusa (Libos et al., 2003), os impactos dos diferentes usos do solo (Caovilla et al., 2005; Pinheiro et al., 2009) ou, ainda, estimar o aporte de nutrientes (Bertol et al., 2005; Diel et al., 2007; Piovesan et al., 2009).

Em geral, os estudos tratam de forma separada, as concentrações e cargas transportadas de determinadas substâncias. A carga representa a quantidade dos sais transportados através de uma seção de controle. A avaliação das cargas anuais em um sistema hidrológico é requerida no processo de gestão dos constituintes presentes na água (Pinheiro \& Deschamps, 2008). Neste processo, podem ser realizadas estimativas das contribuições das fontes de poluição difusa e pontual (Vervier et al., 1999; Dorioz et al., 2004).Assim,o objetivo deste trabalho foi quantificar, em área agrícola, as concentrações e cargas transportadas de nitrato e fosfato (inorgânico total) e comparar as concentrações com as Resoluções CONAMA nº. 357/2005 e nº. 420/2009.

\section{MATERIAL E MÉTODOS}

Aárea de estudo é a Bacia do Ribeirão Concórdia, localizada no município de Lontras, na vertente atlântica do estado de Santa Catarina, Brasil (Figura 1). O Ribeirão Concórdia é afluente do rio Lontras e este é afluente do rio Itajaí-Açu. A bacia está inserida entre as sete bacias monitoradas pelo Projeto de Recuperação Ambiental e de Apoio ao Pequeno Produtor Rural (PRAPEM/MICROBACIAS) desenvolvido pela Secretaria de Estado da Agricultura e Desenvolvimento Rural de Santa Catarina.

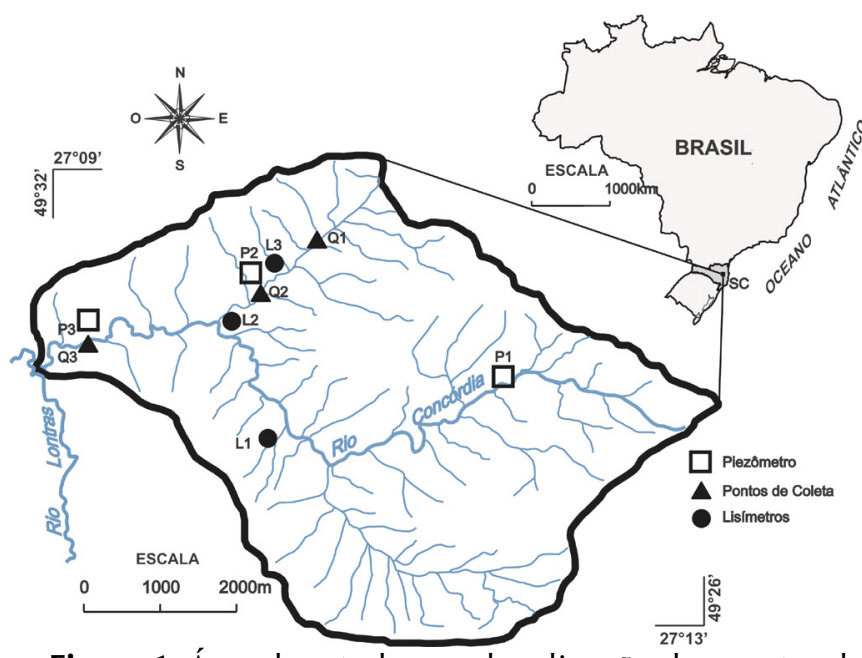

Figura 1. Área de estudo com localização dos pontos de instalação dos lisímetros L1(LR1 e LD1), L2 (LR2 e LD2) e L3 (LR3 e LD3), piezômetros P1, P2 e P3 e as seções fluviométricas Q1, Q2 e Q3

A Bacia do Ribeirão Concórdia possui uma área de drenagem de $30,74 \mathrm{~km}^{2}$. Os solos predominantes na bacia são Cambissolo, Argissolo e Gleissolo e a região climática, de acordo com a classificação de Thornthwaite, é definida como sendo de clima Mesotérmico Úmido do tipo B3 B'3 ra', sem estação seca definida e com precipitações anuais entre 1600 e $1800 \mathrm{~mm}$. A vegetação original da área pertence à Floresta Ombrófila Densa.

Os principais usos do solo estão destinados à mata nativa $(47,61 \%)$, pastagem $(20,35 \%)$ e ao plantio de milho $(9,29 \%)$. Em termos de população, o levantamento efetuado pela EPAGRI (2005) identificou a presença de 600 habitantes, os quais criam, em sistema extensivo, 31350 aves, 2520 cabeças de suínos, 9000 cabeças de bovinos, 700 cabeças de equinos e 220 cabeças de ovinos. O levantamento não apresenta a distribuição espacial desses animais, porém percebe-se que eles estão bem distribuídos ao longo da superfície da bacia.

Foi efetuado o monitoramento de águas superficiais e subterrâneas. Coletas de água foram realizadas em três seções 
fluviométricas (Q1, Q2 e Q3), três lisímetros (LR1, LR2 e LR3 para escoamento superficial e LD1, LD2 e LD3 para drenagem) e três poços piezométricos, distribuídos no interior da bacia, conforme apresentado na Figura 1. Em cada amostra foram determinadas as concentrações dos íons nitrato e fosfato (inorgânico total). Nas seções fluviométricas e nos escoamentos do lisímetro L1 foram determinadas as vazões, o que permitiu o cálculo das cargas transportadas pelo fluxo de água.

Os lisímetros de formato cúbico, do tipo volumétrico de drenagem, contêm amostras de solo indeformadas, com volume de $1 \mathrm{~m}^{3}$ e base de $1 \mathrm{~m}^{2}$. Eles foram confeccionados conforme descrito por Oliveira et al. (2010). O material usado para a construção dos lisímetros foi placa de acrílico de 8 $\mathrm{mm}$ de espessura. Foram instalados sistemas de captação dos escoamentos denominados LR1, LR2 e LR3, respectivamente, para os 3 lisímetros, e o escoamento de drenagem na base, denominados LD1, LD2 e LD3. A água de escoamento foi transportada através de tubos de PVC de $25 \mathrm{~mm}$ de diâmetro para galões de 5 e de $50 \mathrm{~L}$, nos quais ficaram armazenados até a realização da medida do volume escoado e coleta de amostra para determinação das concentrações das espécies químicas.

Nos lisímetros foram mantidas as condições naturais do solo e das atividades agrícolas desenvolvidas nas áreas em que foram instalados. Os lisímetros L1, L2 e L3, foram instalados em área de plantio de milho (Zea mays) de cebola (Allium cepa) e de pastagem, respectivamente.

Os piezômetros foram confeccionados conforme Santoro et al. (2007) em tubos de PVC com $60 \mathrm{~mm}$ de diâmetro, introduzidos no solo em orifícios abertos com trado tipo holandês até atingir a camada impermeável, quando então se colocou uma camada de areia média com $0,40 \mathrm{~m}$ de espessura, apoiando-os sobre esta camada. No tubo de PVC foram feitas ranhuras e colocada uma camada de geotêxtil para permitir a passagem de água e impedir a passagem de partículas de solo ou de areia para o interior do filtro e, na parte superior, foi feita uma impermeabilização de $0,50 \mathrm{~m}$ com concreto. $\mathrm{O}$ poço piezométrico, denominado $\mathrm{P} 1$, está localizado em uma área de mata ciliar e os poços $\mathrm{P} 2$ e $\mathrm{P} 3 \mathrm{em}$ área de pastagem, este último localizado próximo ao exutório da bacia. As profundidades dos piezômetros são variáveis sendo inferiores a $5,00 \mathrm{~m}$, de acordo com a profundidade do lençol freático do local.

O monitoramento foi realizado em um período de 109 dias, compreendido entre 07/06/2011 e 03/10/2011. Nas seções fluviométricas e nos piezômetros, as coletas foram realizadas com frequência quinzenal, e nos lisímetros, após a ocorrência de eventos de precipitação expressivos, geralmente, superiores a $10 \mathrm{~mm}$. Foram coletadas 49 amostras nos lisímetros, 23 nos piezômetros e 30 nas estações fluviométricas, perfazendo o total de 102 amostras.

No dia 1 de julho de 2011 foi realizada uma aplicação de superfosfato triplo (NPK 9 - 16 - 12) para o plantio de aveia preta (Avena strigosa) no L1 e de cebola (Allium cepa) no L2. A aplicação se fez de acordo com as necessidades do solo definidas após realização de análise do mesmo. A quantidade aplicada foi de $350 \mathrm{~kg} \mathrm{ha}^{-1}$ para os solos dos dois lisímetros. A adição da mesma quantidade foi uma questão metodológica adotada, já que no L2 as quantidades recomendadas seriam de $200 \mathrm{~kg} \mathrm{ha}^{-1}$.
Nos lisímetros, tanto para o escoamento superficial quanto para a drenagem, as amostras de água coletadas nos galões foram transferidas para frascos de polietileno de $100 \mathrm{~mL}$; já as amostras dos piezômetros foram coletadas com o auxílio de seringa acoplada a um tubo de silicone. A seringa foi introduzida no interior do piezômetro e por meio de seguidas sucções, amostras de $100 \mathrm{~mL}$ foram coletadas e armazenadas em frasco de polietileno, armazenadas em caixa com isolamento térmico e transportadas ao Laboratório de Hidrologia da Fundação Universidade Regional de Blumenau, FURB, para determinação das concentrações dos íons nitrato e fosfato.

A concentração de nitrato $\left(\mathrm{NO}_{3}^{-}\right)$e do fosfato inorgânico total $\left(\mathrm{PO}_{4}^{3-}\right)$ foi obtida em cromatógrafo de troca iônica ICS - 90 , marca Dionex, equipado com uma coluna de separação aniônica (IonPac AS22 Analytical - 4 x $250 \mathrm{~mm}$ ), uma supressora (Anion Self - Regenerating Supressor - ASRS $3004 \mathrm{~mm}$ ) e um detector de condutividade. As condições de injeção das amostras foram: Injeção da amostra: $10 \mu \mathrm{L}$; Temperatura ambiente; Taxa de fluxo: $1,2 \mathrm{~mL} \mathrm{~min}^{-1}$; Eluente: $4,5 \mathrm{mM} \mathrm{Na}_{2} \mathrm{CO}_{3} / 1,4 \mathrm{mM} \mathrm{NaHCO}_{3}$; Condutividade da linha base: 19 a $23 \mu \mathrm{S}$; Supressor: aniônico autorregenerante; Solução estoque: $\mathrm{NaHCO}_{3} 100 \mathrm{mM}$; Corrente aplicada: $31 \mathrm{~mA}$. As curvas de calibração foram realizadas com os padrões nitrato e fosfato.

Na seção fluviométrica Q1 a vazão é medida através de um vertedor misto, composto de uma estrutura de concreto, de formato triangular de $0,25 \mathrm{~m}$ de altura e retangular com altura de $0,64 \mathrm{~m}$. As lâminas de água sobre o vertedor são medidas com um sensor automático de nível, do tipo boia produzido pela OTT, marca Thalimedes. As vazões são obtidas pelas equações hidráulicas aplicadas para este tipo de vertedor.

As seções fluviométricas foram equipadas com sensores automáticos de nível, da OTT, da marca Thalimedes, monitorando a cota em intervalos regulares de $10 \mathrm{~min}$. Para conversão das cotas em descargas foram construídas, nas seções Q2 e Q3, curvas-chave estabelecidas por meio da medição de vazão em diferentes cotas. As vazões foram medidas com uso de um molinete, marca OTT, C-31.

As concentrações de nitrato e fosfato inorgânico total foram comparadas com as Resoluções CONAMAn ${ }^{\circ} .357 / 2005$, quando se tratava das águas de escoamento superficial nos lisímetros e do escoamento nas seções fluviométricas e com CONAMA ${ }^{\circ}$. 420/2009, quando se tratava das águas de drenagem dos lisímetros ou subterrâneas dos piezômetros. No entanto, na primeira resolução citada consta apenas a concentração recomendada para o nutriente nitrato e o fósforo total. Neste sentido foi necessário transformar o valor de fósforo total recomendado pela Resolução $\mathrm{n}^{\circ} .357 / 2005$, em fosfato. Assim se obteve, a partir da relação $\mathrm{PO}_{4}$ $=\mathrm{P}_{\text {total }} * 3,066 \mathrm{o}$ valor $0,05 \mathrm{mg} \mathrm{L}^{-1}$, recomendado para ambientes intermediários e de classe 2 (classe de enquadramento das águas da bacia do Ribeirão Concórdia) a concentração $0,1533 \mathrm{mg} \mathrm{L}^{-1}$, como valor recomendado de fosfato.

Calculou-se a carga para as três seções fluviométricas $(\mathrm{Q} 1$, Q2 e Q3) utilizando-se a Eq. 1.

$$
\operatorname{carg} a=\frac{\sum_{i=1}^{n} \mathrm{Ci} \times \mathrm{Qi}}{\sum_{\mathrm{i}=1}^{\mathrm{n}} \mathrm{Qi}} \times \overline{\mathrm{Q}}
$$


donde:

$\mathrm{Ci}$ - concentração da amostra i

Qi - vazão média diária do escoamento no rio no dia da coleta da amostra $\mathrm{i}$

Q - vazão média do rio no período de monitoramento

Calculou-se a carga para o lisímetro L1 a partir do escoamento na superfície (LR1) e na solução drenada (LD1) pela Eq. 2.

$$
\operatorname{carg} a=\frac{\sum_{i=1}^{n} \mathrm{Ci} \times \mathrm{Vi}}{\sum_{\mathrm{i}=1}^{\mathrm{n}} \mathrm{Vi}} \times \overline{\mathrm{V}}
$$

donde:

$\mathrm{Ci}$ - concentração da amostra $\mathrm{i}$

$\mathrm{Vi}$ - volume de escoamento superficial ou de drenagem armazenado no recipiente em que foi coletada a amostra $\mathrm{i}$

$\mathrm{V}$ - volume de escoamento total superficial ou de drenagem, durante o período de monitoramento

Os valores das vazões e das concentrações de nitrato e fosfato permitiram construir uma curva de frequência indicando quando a concentração máxima foi ultrapassada. A frequência foi determinada pela aplicação da Eq. 3 .

$$
\mathrm{F}=\frac{\mathrm{m}}{\mathrm{n}+1} \times 100
$$

donde:

m - é o número de ordem, quando a série é classificada em ordem crescente

n - é o tamanho da amostra.

\section{RESULTADOS E DISCUSSÃO}

Na Figura 2 são apresentadas as concentrações de nitrato e fosfato e a frequência com que são encontradas na água superficial (água escoada superficialmente em lisímetro e água das seções fluviométricas) e subterrânea (água drenada de lisímetro e água de piezômetro) da Bacia do Ribeirão Concórdia.

A concentração do nitrato em água de escoamento superficial excedeu o padrão estabelecido pela Resolução CONAMA n ${ }^{\circ}$. $357 / 2005$ no lisímetro LR1, em todas as frequências e no lisímetro LR2 o limite foi excedido a partir da frequência $42,86 \%$. Os valores máximos encontrados foram 151,37 e $458,22 \mathrm{mg} \mathrm{L}^{-1}$, respectivamente (Figura 2A); já no lisímetro LR3 a concentração de nitrato ficou abaixo do limite estabelecido pela Resolução CONAMA n ${ }^{\circ} .357 / 2005$ (inferior a $10 \mathrm{mg} \mathrm{L}^{-1}$ ) em todas as frequências. Os valores obtidos no escoamento superficial dos lisímetros, LR1 e LR2, podem ser explicados pela aplicação de nitrogênio no solo, o que não se repetiu no lisímetro LR3, no qual se observa baixa concentração de nitrato ficando,durante todo o tempo, abaixo do limite estabelecido por esta resolução (Figura 2A).
As concentrações de fosfato ultrapassaram os limites estabelecidos pela CONAMA n ${ }^{\circ}$. 357/2005 nos lisímetros, LR1 e LR2, em todas as frequências e no LR3 somente a partir da frequência $12,50 \%$. Já as concentrações máximas de fosfato obtidas foram 7,43, 20,15 e 1,09 $\mathrm{mg} \mathrm{L}^{-1}$ respectivamente para LR1, LR2 eLR3 (Figura 2B).

A concentração de nitrato na água de drenagem excedeu a Resolução CONAMA nº . 420/2009 nos lisímetros LD1 e LD2, em todas as frequências. Os valores máximos obtidos nesses dois lisímetros, foram de119,42 e 117,51 $\mathrm{mg} \mathrm{L}^{-1}$, respectivamente. Por outro lado, no lisímetro LD3 a concentração de nitrato ficou abaixo do limite estabelecido pela CONAMA n ${ }^{\circ}$. 420/2009 (inferior a $10 \mathrm{mg} \mathrm{L}^{-1}$ ) em todas as frequências (Figura 2C).

A Resolução CONAMA nº. 420/2009 não estabelece padrão para nenhuma forma de fósforo. Assim, a comparação foi desenvolvida com base nos padrões da água superficial. As concentrações do fosfato na água de drenagem dos três lisímetros ultrapassaram o valor limite estabelecido pela Resolução CONAMA n ${ }^{\circ}$. 357/2005, a partir da frequência de $45,45 \%$ para os lisímetros LD1 e LD3 e a partir de $54,55 \%$ para o lisímetro LD2 sendo que as concentrações máximas foram $0,17,0,32$ e $0,35 \mathrm{mg} \mathrm{L}^{-1}$, respectivamente (Figura 2D).

Por se tratar de um solo com características de baixa porosidade (inferior a 50\%), pode-se observar uma contribuição maior dos nutrientes nitrato e fosfato nas amostras de escoamento superficial dos lisímetros de vez que os mesmos podem ser transportados até os corpos de água já que a infiltração nesse tipo de solo é dificultada pela baixa porosidade. Neste sentido, nas amostras de drenagem dos lisímetros a menor concentração desses nutrientes pode ser explicada pelo acúmulo dos mesmos ao longo do tempo. Outra explicação para a redução da concentração de nitrato em águas de drenagem se deve ao fato do nitrogênio disponível no solo ser decorrente da mineralização e da decomposição da matéria orgânica, em que os micro-organismos transformam o $\mathrm{N}$ orgânico nas formas amoniacal $\left(\mathrm{NH}_{4}^{+}\right)$e nítrica $\left(\mathrm{NO}_{3}^{-}\right)$disponibilizando-os às plantas (Duarte, 2006).

A concentração de nitrato na água subterrânea excedeu a Resolução CONAMA n ${ }^{\circ}$. 420/2009 nos piezômetros P3 e P1 a partir das frequências 37,50 e 71,43\%, respectivamente; já os valores máximos de nitrato obtidos nesses dois piezômetros foram 28,46 e 31,38 $\mathrm{mg} \mathrm{L}^{-1}$, respectivamente. Por outro lado, no piezômetro $\mathrm{P} 2$ a concentração de nitrato ficou abaixo de $10 \mathrm{mg}$ $\mathrm{L}^{-1}$, limite máximo estabelecido por esta resolução, em todas as frequências (Figura 2E). Corroborando com a presente pesquisa, Darwish et al. (2011) encontraram, estudando a contaminação de águas subterrâneas por nitrato, no Líbano, concentrações elevadas desse nutriente em áreas agrícolas chegando a $200 \mathrm{mg}$ $\mathrm{L}^{-1}$, ressaltando a grande contribuição que o uso de fertilizantes pode gerar à degradação deste meio aquático.

A Resolução CONAMA nº. 420/2009 não estabelece padrão para nenhuma forma de fósforo. Assim, a comparação foi desenvolvida com base nos padrões da água superficial. Os valores de fosfato foram maiores que os do limite estabelecido pela Resolução CONAMA n ${ }^{\circ}$. 357/2005 nos três piezômetros, a partir das frequências 37,50\% para P2 e P3 e a partir de $57,14 \%$ para $\mathrm{P} 1$, com concentrações máximas de $0,31,0,26$ e $0,17 \mathrm{mg} \mathrm{L}^{-1}$, respectivamente (Figura $2 \mathrm{~F}$ ). Segundo Brito et 
A.

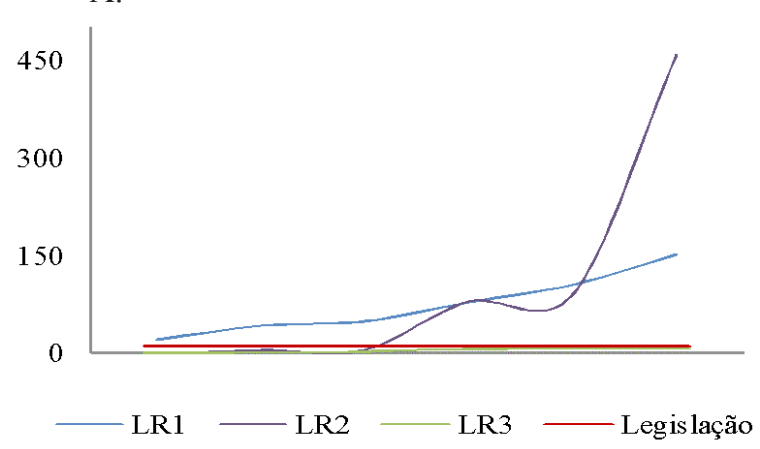

C.

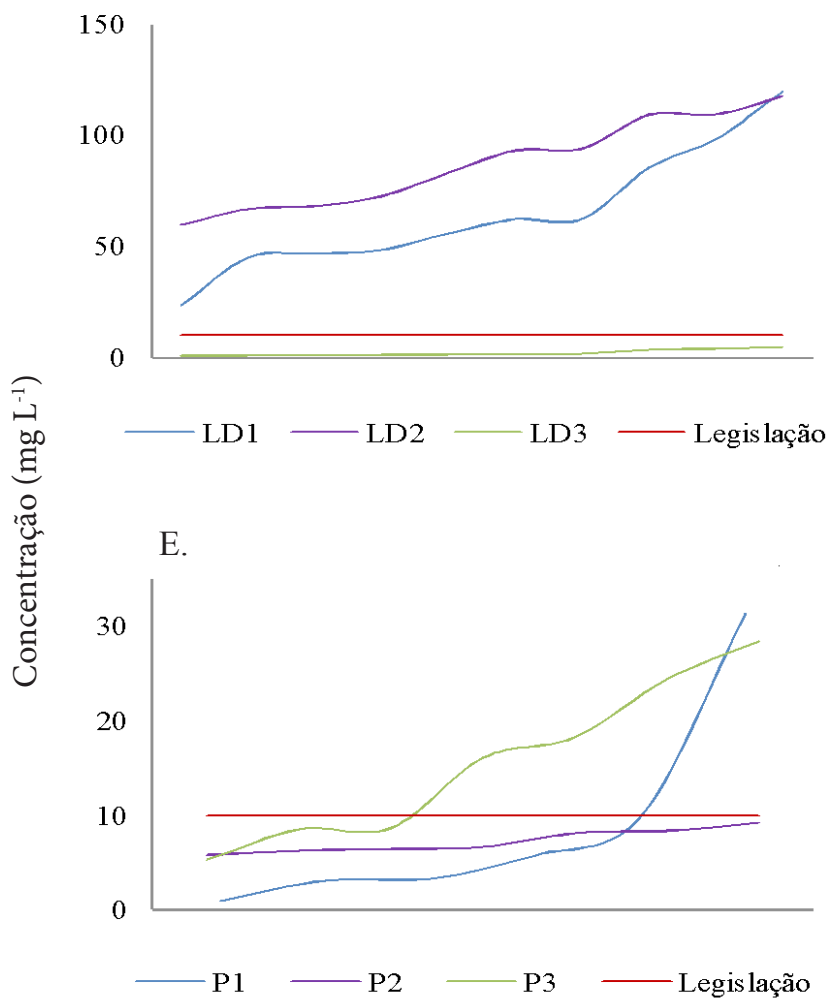

G.

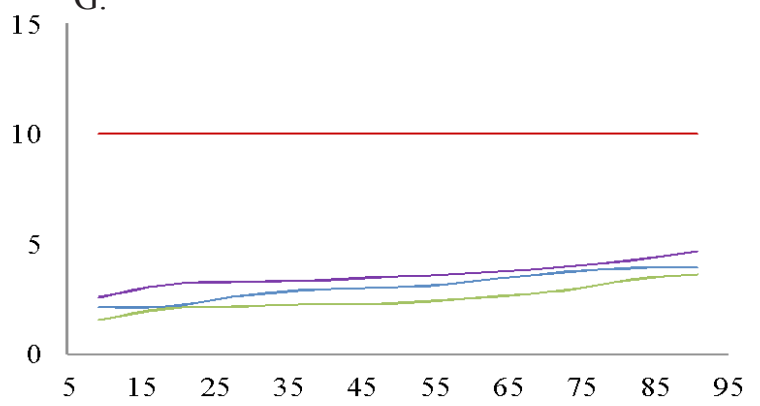

Q.1 Q Q.2 Q Q.3 - Legislação
B.

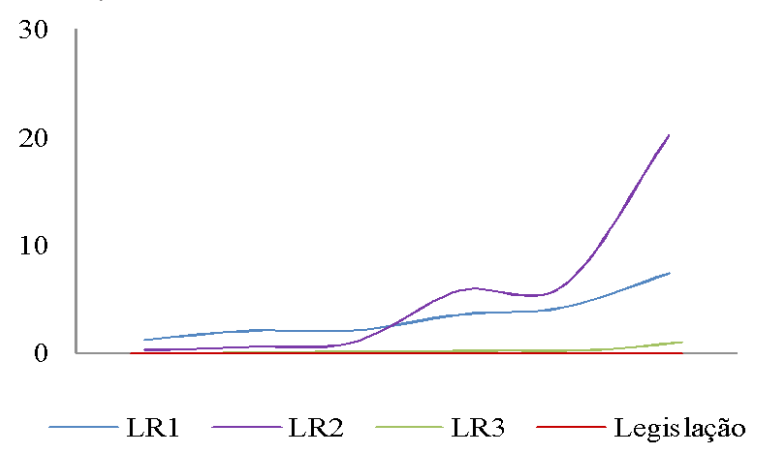

D.

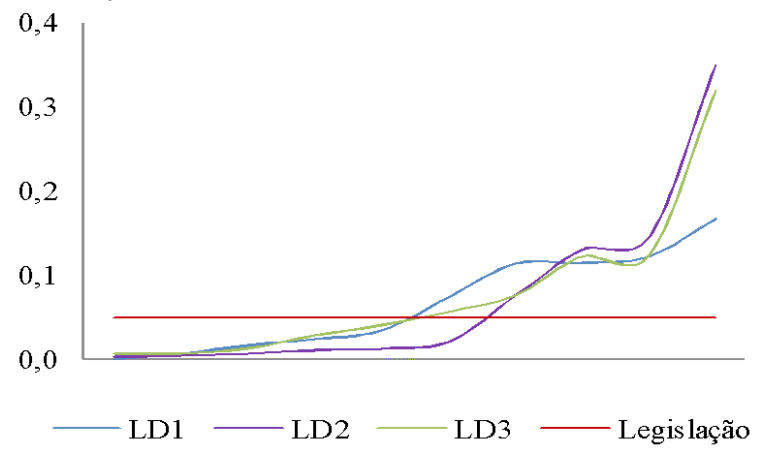

F.

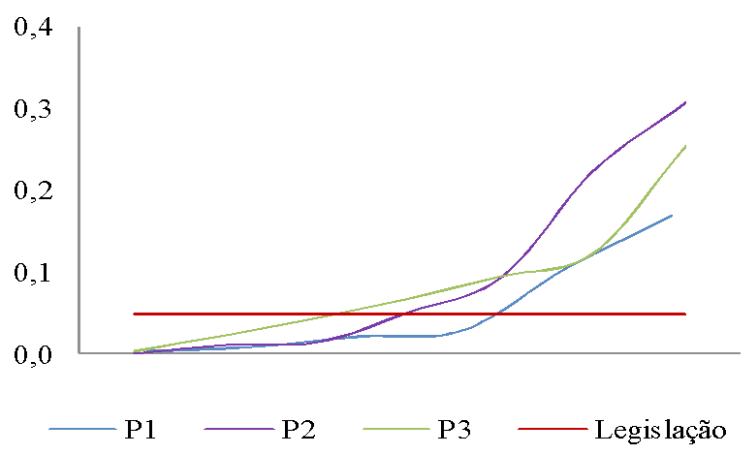

$\mathrm{H}$.

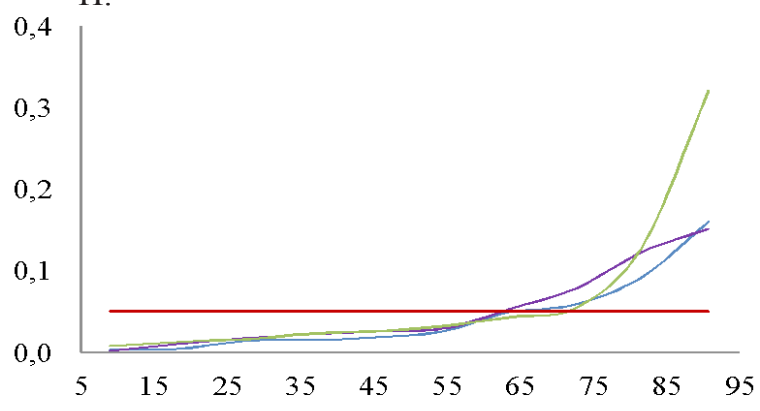

Q.1 Q.2 Q.3 Legislação

Frequência (\%)

Figura 2. Frequência das concentrações de nitrato e fosfato em água de escoamento superficial - lisímetros LR1, LR2 e LR3 (A - nitrato, B - fosfato), em água de drenagem - lisímetros LD1, LD2 e LD3 (C - nitrato, D - fosfato), em água subterrânea - piezômetros P1, P2 e P3 (E - nitrato, F - fosfato) e em água das seções fluviométricas - Q1, Q2 e Q3 (G - nitrato, H - fosfato). Legislação: CONAMA nº. 357/2005 e CONAMA n. 420/2009 
al. (2009) a cobertura vegetal da bacia, especialmente na mata ciliar adjacente aos cursos de água, contribui significativamente para o aporte de nutrientes no rio e atua no controle da descarga e no comprimento de sedimentos, estando as atividades agropecuárias intimamente ligadas aos processos de erosão e ao transporte de seus nutrientes e sedimentos. Tal fato pode ser observado no piezômetro P1, instalado em área de mata ciliar, ressaltando o aporte dos nutrientes nitrato e fosfato nas águas subterrâneas.

Neste sentido e de acordo com Ator \& Ferrari (1997) águas profundas sob solos vegetados por florestas, normalmente mais protegidos, apresentam menores riscos de degradação se comparadas com as águas profundas de áreas cultivadas situação não observada no presente trabalho para o nitrato, pois sua concentração foi menor nos piezômetros $\mathrm{P} 2$ e P3 os quais, por outro lado, estão localizados em áreas de pastagem em que quais não ocorre adição de fertilizante. A maior concentração de nitrato no piezômetro P1, localizado em uma área de mata ciliar, pode ser explicada pela liberação de nutrientes provinda da decomposição da biomassa.

Os valores de nitrato nas seções fluviométricas, Q1, Q2 e Q3, estão de acordo com CONAMA n ${ }^{\circ}$. 357/2005, sendo as concentrações máximas de 3,91, 4,74 e 3,62 $\mathrm{mg} \mathrm{L}^{-1}$, respectivamente (Figura 4G). Por outro lado, a concentração de fosfato foi superior ao estabelecido por CONAMA n.357/2005 na frequência 63,64\% para os pontos de coleta Q1 e Q3 e na frequência de $54,55 \%$ para Q2. Os valores máximos foram de $0,16,0,32$ e $0,15 \mathrm{mg} \mathrm{L}^{-1}$, respectivamente (Figura $2 \mathrm{H}$ ).

De forma geral, as concentrações de nitrato e fosfato são maiores nos lisímetros o devido à aplicação direta de fertilizantes com compostos de nitrogênio e fósforo sobre os diferentes cultivos, milho (L1), cebola (L2) e pastagem (L3). Porém, na medida com que estes compostos são transportados para as águas profundas e ao chegar ao rio, suas concentrações diminuem consideravelmente, devido a fatores de atenuação no escoamento fluvial, como absorção pela biomassa, desnitrificação e sedimentação, entre outros (Gomes et al., 2008).

As altas concentrações de nitrato encontradas nos pontos de coleta (lisímetros, piezômetros e seções fluviométricas) podem ser justificadas pelo fato do ânion nitrato ser fracamente retido nas cargas positivas dos colóides e por permanecer mais tempo em solução, principalmente nas camadas superficiais do solo nas quais a matéria orgânica acentua o caráter eletronegativo da fase sólida (repelindo o nitrato). Desta forma, na solução do solo o nitrato fica propenso ao processo de transporte e, ao longo do tempo, pode haver um incremento considerável nos teores de nitrato, nas águas profundas. O inverso acontece com o fosfato uma vez que, quando aplicado na adubação,ele ocupa as cargas positivas disponíveis ficando retido nos colóides (Resende, 2002).

Quanto aos resultados das cargas de nitrato e de fosfato as mesmas são apresentadas na Tabela 1 . O elevado valor da carga de nitrato no ponto LD1 $\left(13,52 \mathrm{~kg} \mathrm{ha}^{-1}\right.$ ano $\left.^{-1}\right)$ está associado ao uso de fertilizantes que visam à reposição de nutrientes no solo para a atividade agrícola. Verifica-se grande discrepância entre os valores de nitrato em LD1 (drenagem) e LR1 (escoamento superficial) o que evidencia a lixiviação do nitrato, essencial para o desenvolvimento das plantas e, por outro lado, altamente favorável à degradação da água, quando em excesso.

As águas de drenagem (LD1) transportaram cargas de nitrato e fosfato superiores às de escoamento superficial (LR1); estas, por sua vez, transportaram cargas equivalentes às das seções fluviométricas (Q1, Q2 e Q3) conforme observado na Tabela 1. As cargas variaram entre 0,006 e $0,053 \mathrm{~kg} \mathrm{ha}^{-1}$ ano $^{-1}$ para o fosfato e de 0,33 e $13,52 \mathrm{~kg} \mathrm{ha}^{-1} \mathrm{ano}^{-1}$ para o nitrato. Tais resultados diferem dos obtidos por outros autores, como Quilbé et al. (2006) que, ao estimar a perda média de nutrientes na Bacia do Rio Beaurivage, situada em Quebec, Canadá, com 32\% de atividade agrícola, encontraram $1,09 \mathrm{~kg} \mathrm{ha}^{-1} \mathrm{ano}^{-1}$ para o fósforo total e $8,12 \mathrm{~kg} \mathrm{ha}^{-1}$ ano $^{-1}$ para o nitrogênio total;já Kyllmar et al. (2006), observaram, em bacias na Suécia, perdas anuais de nitrogênio total variando entre $2 \mathrm{e} 41 \mathrm{~kg} \mathrm{ha}^{-1} \mathrm{ano}^{-1} \mathrm{e}$ de fósforo total entre 0,1 a $0,9 \mathrm{~kg} \mathrm{ha}^{-1} \mathrm{ano}^{-1}$.

Tabela 1. Cargas transportadas de nitrato e fosfato nas seções fluviométricas (Q1, Q2 e Q3) e no lisímetro (L1) na bacia do ribeirão Concórdia, Lontras, SC

\begin{tabular}{|c|c|c|}
\hline \multirow{2}{*}{ Ponto de coleta } & Nitrato & Fosiato \\
\hline & \multicolumn{2}{|c|}{$\mathrm{kg} \mathrm{ha}^{-1} \mathrm{ano}^{-1}$} \\
\hline LR1 & 0,33 & 0,017 \\
\hline LD1 & 13,52 & 0,053 \\
\hline Q1 & 0,44 & 0,006 \\
\hline Q2 & 0,66 & 0,010 \\
\hline Q3 & 0,36 & 0,011 \\
\hline
\end{tabular}

LR1 e LD1: lisímetro 1 - águas de escoamento superficial e águas de drenagem, respectivamente; Q1, Q2 e Q3: seções fluviométricas

Quando comparado com o presente estudo, Pinheiro \& Deschamps (2008) encontraram, em um estudo realizado em área agrícola situada no município de Timbó, SC, Brasil, maiores cargas para o fosfato variando de 6,51 a 62,79 $\mathrm{kg} \mathrm{ha}^{-1}$ ano $^{-1}$ e menores cargas para nitrato, variando de 1,13 a $4,97 \mathrm{~kg} \mathrm{ha}^{-1} \mathrm{ano}^{-1}$.

Ressalta-se que nas seções fluviométricas há, para o fosfato, uma contribuição de carga crescente em relação à nascente para a Foz do Ribeirão Concórdia o que pode ocorrer devido às contribuições pontuais dos lançamento de esgotos domésticos tratados em sistemas individuais de tratamento e de dejetos animais.

\section{ConclusõES}

1. As concentrações de nitrato nas seções fluviométricas Q1, Q2 e Q3, no lisímetro L3 com pastagem, tanto do escoamento superficial quanto da drenagem e no piezômetro P2, estão de acordo com o padrão estabelecido pelas Resoluções CONAMA no. 357/2005 e n. 420/2009.

2. As concentrações de fosfato nas seções fluviométricas Q1, Q2 e Q3, nos lisímetros L1, L2 e L3, tanto do escoamento superficial quanto da drenagem e nos piezômetros P1, P2 e P3, superaram os padrões das Resoluções CONAMAn ${ }^{\circ}$. 357/2005 e $\mathrm{n}^{\mathrm{o}}$. 420/2009.

3. As águas de drenagem nos lisímetros transportaram cargas de nitrato e de fosfato superiores àquelas do escoamento superficial e, estas, por sua vez, transportaram cargas da mesma ordem de grandeza das águas fluviais. 


\section{Agradecimentos}

Ao CNPq (Processo $\left.\mathrm{n}^{\circ} .301156 / 2008-5\right)$ pela bolsa de produtividade do primeiro autor, e à CAPES, pelas bolsas de mestrado do terceiro e quarto autores.

\section{LITERATURA CITADA}

Ator, S. W.; Ferrari, M. I. Nitrate and selected pesticides in ground water of the Mid-Atlantic Region. United States Geological Survey/Environmental Protection Agency, 1997. $<$ http://md.water.usgs.gov/publications/wrir-97-4139/html. htm>. 03 Nov. 2011.

Bertol, O. J.; Rizzi, N. E.; Favaretto, N. ; Lavoranti, O. J. Perdas de nitrogênio via superfície e subsuperfície em sistema de semeadura direta. Floresta, v.35, p.429-442, 2005.

Brito, R. N. R.; Asp, N. E.; Beasley, C. R.; Santos, H. S. S. Características sedimentares fluviais associadas ao grau de preservação da mata ciliar - Rio Urumajó, Nordeste Paraense. Revista Acta Amazônica, v.39, p.173-180, 2009.

Caovilla, F. A.; Sampaio, S. C.; Pereira, J. O.; Boas, M. A. V.; Gomes, B. M.; Figueirêdo, A. C. Lixiviação de nutrientes provenientes de águas residuárias em colunas de solo cultivado com soja. Revista Brasileira de Engenharia Agrícola e Ambiental, v.9, p.283-287, 2005.

CONAMA - Conselho Nacional do Meio-Ambiente. Resolução $n^{\circ} .357$ de 17 de Março de 2005. Dispõe sobre a classificação dos corpos de água e diretrizes ambientais para o seu enquadramento, bem como estabelece as condições e padrões de lançamento de efluentes, e dá outras providências. Publicação Diário Oficial da União, Poder Executivo, Brasília, DF, n.87, p.44, 2005.

CONAMA - Conselho Nacional do Meio-Ambiente. Resolução $n^{\circ} .420$ de 28 de Dezembro de 2009. Dispõe sobre critérios e valores orientadores de qualidade do solo quanto à presença de substâncias químicas e estabelece diretrizes para o gerenciamento ambiental de áreas contaminadas por essas substâncias em decorrência de atividades antrópicas. Publicação Diário Oficial da União, Poder Executivo, Brasília, DF, n.249, p.81-84, 2009.

Darwish, T.; Atallah, T.; Francis, R.; Saab, C.; Jomaa, I.; Shaaban, A.; Sakka, H.; Zdruli, P. Observations on soil and groundwater contamination with nitrate: A case study from Lebanon-East Mediterranean. Agricultural Water Management, v.99, p.74-84, 2011.

Diel, M.; Castilhos, R. M. V.; Sousa, R. O.; Valh, L. C.; Silva, J. B. Nutrientes na água para irrigação de arroz na Região Sul do Rio Grande do Sul, Brasil. Ciência Rural, v.37, p.102-109, 2007.

Dorioz, J. M.; Quetin, P.; Lazzarotto, J.; Orand, A. Bilan $\mathrm{du}$ phosphore dans un bassin versant du lac Léman: conséquences pour la détermination de l'origine des flux exportés. Revuedes Sciences de l'Eau, v.17, p.329-354, 2004.

Duarte, F. M. Perdas de nitrogênio por volatilização de amônia e eficiência da adubação nitrogenada na cultura do arroz irrigado. Santa Maria: UFSM. 2006. 87p. Dissertação Mestrado
EPAGRI - Empresa de Pesquisa Agropecuária e de Extensão Rural de Santa Catarina. Projeto Microbacias 2: Relatório síntese - monitoramento socioeconômico. Dez. 2005. $<$ http://www.microbacias.sc.gov.br>. 26 Jul. 2012.

Gburek, W. J.; Sharpley, A. N. Hydrologic controls on phosphorus loss from upland agricultural watersheds. Journal of Environmental Quality, v.27, p.267-277, 1998.

Gomes, M. A. F.; Souza, M. D.; Boeira, R. C.; Toledo, L. G. Nutrientes vegetais no meio ambiente: ciclos bioquímicos, fertilizantes e corretivos. Jaguariúna: Embrapa Meio Ambiente. 2008. 61p. Documentos, 66

Kyllmar, K.; Carlsson, C.; Gustafson, A.; Ulén, B.; Johnsson, H. Nutrient discharge from small agricultural catchments in Sweden: Characterisation and trends. Agriculture, Ecosystems and Environment, v.115, p.15-26, 2006.

Libos, M.; Rotunno Filho, O. C.; Zeilhofer, P. Modelagem da poluição não pontual na bacia do rio Cuiabá baseada em Geoprocessamento. Revista Brasileira de Recursos Hídricos, v.8, p.115-135, 2003.

Merten, G. H.; Minella, J. P. Qualidade da água em bacias hidrográficas rurais: um desafio atual para a sobrevivência futura. Agroecologia e Desenvolvimento Rural Sustentável, v.3, p.33-38, 2002.

Monteiro, V. P.; Pinheiro, J. C. Critério para implantação de tecnologias de suprimentos de água potável em municípios cearenses afetados pelo alto teor de sal. Revista de Economia e Sociologia Rural, v.42, p.365-387, 2004.

Oliveira, N. T.; Castro, N. M. R.; Goldenfum, J. A. Influência da palha no balanço hídrico em lisímetros. Revista Brasileira de Recursos Hídricos, v.15, p.93-103, 2010.

Pinheiro, A.; Deschamps, F. C. Transporte de ortofosfato e de nitrato na Microbacia do Ribeirão Fortuna, SC. Revista Brasileira de Engenharia Agrícola e Ambiental, v.12, p.318325, 2008.

Pinheiro, A.; Teixeira, L. P.; Kaufmann, V. Capacidade de infiltração de água em solos sob diferentes usos e práticas de manejo agrícola. Revista Ambiente e Água - An Interdisciplinary Journal of Applied Science, v.4, p.188199, 2009.

Pinto, L. V. A.; Ferreira, E.; Botelho, S. A.; Davide, A. C. Caracterização física da Bacia Hidrográfica do Ribeirão Santa Cruz, Lavras, MG e uso conflitante da terra em suas áreas de preservação permanente. Cerne, v.11, p.49-60, 2005.

Piovesan, R. P.; Favaretto, N.; Pauletti, V.; Motta, A. C. V.; Reissmann, C. B. Perdas de nutrientes via subsuperfície em colunas de solo sob fertilização mineral e orgânica. Revista Brasileira de Ciência do Solo, v.33, p.757-766, 2009.

Quilbé, R.; Rousseau, A. L.; Duckemin, M.; Pouli, A.; Gangbazo, G.; Villeneuve, J. P. Selecting a calculation method to estimate sediment and nutrient loads in streams: Application to the Beaurivage river (Québec, Canadá). Journal of Hydrology, v.326, p.295-310, 2006.

Resende, Á. V. Agricultura e qualidade da água: Contaminação da água por nitrato. Planaltina: Embrapa Cerrados, 2002.29p. 
Santoro, J.; Diniz, H. N. Correia, N. T.; Carbone, F. R.; Sciotta, L. C. O. Estimativa da recarga do aquífero freático na bacia do rio Uma no município de Taubaté, SP. Revista Ambiente e Água - An Interdisciplinary Journal of Applied Science, n.1, v.2, p.57-82, 2007.

Souza, L. C.; Queiroz, J. E.; Gheyi, H. R. Variabilidade espacial da salinidade de um solo aluvial no semi-árido paraibano. Revista Brasileira de EngenhariaAgrícola eAmbiental, v.4, p.35-40, 2000.

Souza, R. A. S.; Araújo, S. R.; Jesus, V. A. M.; Marques, J. J.; Curi. N.; Guerreiro, M. C. Frações de fosfato em reservatórios de água em Lavras - MG. Ciência e Agrotecnologia, v.31, p.357-365, 2007.
Teodoro, V. L. I.; Teixeira, D.; Costa, D. J. L.; Fuller, B. B. O conceito de bacia hidrográfica e a importância da caracterização morfométrica para o entendimento da dinâmica ambiental local. Revista Uniara, n.20, p.137-157, 2007.

Toledo, L. G.; Nicolella, G. Índice de qualidade de água em microbacia sob uso agrícola e urbano. Scientia Agricola, v.59, p.181-186, 2002.

Vervier, P.; Pinheiro, A.; Fabre, A.; Pinay, G.; Fustec, E. Phosphorus point-source and nitrate nonpoint source pollution along an agricultural river. Water Research, v.33, p.95-104, 1999. 